\title{
Expansion of human airway basal stem cells and their differentiation as 3D tracheospheres
}

Robert E. Hynds, Colin R. Butler, Sam M. Janes and Adam Giangreco

Lungs for Living Research Centre, UCL Respiratory, University College London, London, UK

Running title: Human airway stem cell expansion

Key words: lung, stem cells, epithelial cells, goblet cells, cilia, adult stem cells, cell culture techniques, primary cell culture 


\begin{abstract}
Although basal cells are known to function as human airway epithelial stem cells, analysis of these cells has been limited by in vitro culture techniques that only permit minimal cell growth and differentiation. Here, we report a protocol that dramatically increases the longterm expansion of primary human airway basal cells while maintaining their genomic stability using 3T3-J2 fibroblast co-culture and ROCK inhibition using Y-27632. We also describe techniques for the differentiation and immunofluorescence imaging of these expanded airway stem cells as three-dimensional tracheospheres containing basal, ciliated and mucosecretory cells. This 3D procedure allows investigation of the proximal airway epithelium under more physiologically relevant conditions than those found in traditional monolayer cultures. Together these methods represent a novel platform for improved airway stem cell growth and differentiation that is compatible with high throughput, high content translational lung research as well as human airway tissue engineering and clinical cellular therapy.
\end{abstract}




\section{Introduction}

Human airways represent a key environmental barrier whose dysregulation in diseases such as asthma, COPD, cystic fibrosis and cancer is a major cause of worldwide morbidity and mortality (1). Human airways are composed of a pseudostratified ciliated and mucosecretory epithelium responsible for protecting against inhaled particulate matter, pathogens, and other airborne toxicants. Supporting this epithelium are multipotent basal stem cells characterized primarily by cytokeratin 5 (CK5) and P63 expression $(2,3)$. Given the clear physiological importance of maintaining human airway homeostasis, establishing techniques for investigating basal stem cell growth and differentiation is of significant basic and translational relevance (4).

Historically, the majority of airway stem cell research has involved studies of animal models that exhibit only limited human translational relevance (1). To overcome this, researchers have traditionally used human air-liquid interface (ALI) cultures in which a confluent monolayer of human airway basal cells is cultured in medium containing retinoic acid and grown at an air interface to encourage ciliated and mucosecretory cell differentiation $(5,6)$. Despite the human biological relevance of these ALI models (7), they remain extremely timeconsuming and poorly suited to high throughput, high content translational medicine approaches. In addition, evidence suggests that airway basal stem cells rapidly lose their capacity for multipotent differentiation and undergo premature senescence after only a small number of passages. This failure to maintain airway epithelial stem cells in vitro presents a considerable barrier for their use in translational medicine.

In this chapter, we describe a protocol for improved human airway stem cell expansion that maintains their multipotent differentiation capacity. Originally developed for epidermal keratinocyte stem cells, this technique relies upon the co-culture of primary human epithelial cells with mitotically inactivated 3T3-J2 fibroblast feeder cells (8). Epithelial and J2 feeder cell co-cultures are grown in medium containing the Rho-associated kinase (ROCK) inhibitor Y-27632 (9-11). Successful application of this procedure to airway epithelial cells provides large numbers of basal cells that exhibit physiologically relevant differentiation, karyotype stability and maintenance of telomere length (12). In addition, we also provide 
methods for the differentiation and visualization of human airway basal cells as 3D airway tracheospheres. These techniques build on previous 3D culture systems in which either ciliated or mucosecretory differentiation was achieved $(2,13,14)$. The method described here, based on several recently published studies, permits normal ciliated and mucosecretory cell differentiation $(12,15,16)$ and is compatible with high-throughput, highcontent analyses. Together these methods provide a platform to expand large numbers of airway basal epithelial cells from patient endobronchial biopsy samples and differentiate them in a 3D tracheosphere assay with potential applications in translational medicine, tissue engineering and cellular therapy approaches. 


\section{Materials}

\subsection{Human Airway Epithelial Cell Isolation}

1. RPMI medium with L-glutamine (Gibco, Thermo Fisher). Storage at $4^{\circ} \mathrm{C}$.

2. Dispase (Corning). Storage at $-20^{\circ} \mathrm{C}$.

3. $0.25 \%$ Trypsin-EDTA (Gibco, Thermo Fisher). Storage at $-20^{\circ} \mathrm{C}$.

4. Neutralization medium: Dulbecco's modified Eagle's medium (DMEM) with 4.5g/L Dglucose, L-glutamine and pyruvate (Gibco, Thermo Fisher) plus 10\% fetal bovine serum (FBS) and $1 \mathrm{X}$ Penicillin/Streptomycin (Gibco, Thermo Fisher). Storage at $4^{\circ} \mathrm{C}$.

5. Transport medium: $\alpha$ MEM (Gibco, Thermo Fisher) plus $1 \mathrm{X}$ Penicillin/Streptomycin (Gibco, Thermo Fisher), 1X Gentamicin (Gibco, Thermo Fisher) and 1X Amphotericin B (Fisher Scientific). Storage at $4^{\circ} \mathrm{C}$.

\subsection{T3-J2 Feeder Cell Culture}

1. Dulbecco's modified Eagle's medium (DMEM) with 4.5g/L D-glucose, L-glutamine and pyruvate (Gibco, Thermo Fisher). Storage at $4^{\circ} \mathrm{C}$.

2. Bovine serum (Gibco, Thermo Fisher). Storage at $-80^{\circ} \mathrm{C}$.

3. Penicillin/Streptomycin (Gibco, Thermo Fisher). Storage at $-20^{\circ} \mathrm{C}$.

4. Mitomycin C (Sigma-Aldrich): $0.4 \mathrm{mg} / \mathrm{ml}$ in sterile PBS. Storage at $-20^{\circ} \mathrm{C}$.

5. $0.05 \%$ Trypsin-EDTA (Gibco, Thermo Fisher). Storage at $-20^{\circ} \mathrm{C}, 4^{\circ} \mathrm{C}$ short-term.

6. Complete fibroblast culture medium: $500 \mathrm{ml}$ DMEM plus $45 \mathrm{ml}$ bovine serum and $1 \mathrm{X}$ Penicillin/Streptomycin. Storage at $4^{\circ} \mathrm{C}$.

\subsection{Human Airway Epithelial Cell Culture}

1. Phosphate-buffered saline (PBS; Sigma).

2. Dulbecco's modified Eagle's medium (DMEM) with 4.5g/L D-glucose, L-glutamine and pyruvate (Gibco, Thermo Fisher). Storage at $4^{\circ} \mathrm{C}$.

3. Fetal bovine serum (FBS; Gibco, Thermo Fisher; see Note 1 ). Storage at $-80^{\circ} \mathrm{C}$ longterm, $-20^{\circ} \mathrm{C}$ until use.

4. Penicillin/Streptomycin (Gibco, Thermo Fisher). Storage at $-20^{\circ} \mathrm{C}$.

5. Ham's F-12 nutrient mixture with L-glutamine (Gibco, Thermo Fisher). Storage at $4^{\circ} \mathrm{C}$.

6. Gentamicin (Gibco, Thermo Fisher): 100X. Storage at $4^{\circ} \mathrm{C}$. 
7. Amphotericin B (Fisher Scientific): $250 \mu \mathrm{g} / \mathrm{ml}, 1000 X$. Storage at $-20^{\circ} \mathrm{C}$.

8. Hydrocortisone (Sigma-Aldrich). See Note 2 for storage conditions.

9. Recombinant human EGF (Thermo Fisher). See Note 2 for storage conditions.

10. Insulin, 1,000X stock (Sigma-Aldrich): $5 \mathrm{mg} / \mathrm{ml}$ in distilled water (add glacial acetic acid dropwise to dissolve and sterile filter). Storage at $-20^{\circ} \mathrm{C}$.

11. Cholera Toxin (Sigma-Aldrich): $1 \mathrm{mg} / \mathrm{ml}(11.7 \mu \mathrm{M})$ in distilled water. Storage at $4^{\circ} \mathrm{C}$.

12. Y-27632 (Cambridge Bioscience): $5 \mathrm{mM}$ in distilled water. Storage at $-20^{\circ} \mathrm{C}$.

13. Complete epithelial culture medium: $373 \mathrm{ml}$ serum-containing DMEM (500 ml DMEM plus $50 \mathrm{ml} \mathrm{FBS}$ and 1X Penicillin/Streptomycin), $125 \mathrm{ml} \mathrm{Ham}$ 's F-12, $0.5 \mathrm{ml}$ gentamicin, $0.5 \mathrm{ml}$ Amphotericin B, $0.5 \mathrm{ml}$ hydrocortisone/EGF (see Note 2), $0.5 \mathrm{ml}$

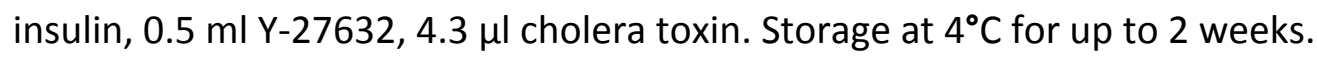

14. Profreeze Chemically Defined Freezing Medium (2X; Lonza).

\subsection{D Human Tracheospheres}

1. Matrigel, basement membrane matrix, growth factor reduced (BD Biosciences; see Note 3). Storage at $-20^{\circ} \mathrm{C}$.

2. Ultra-low attachment 96-well plate (Corning).

3. Bronchial epithelial growth medium with supplements (BEGM; Lonza). Medium stored at $4^{\circ} \mathrm{C}$, supplements at $-20^{\circ} \mathrm{C}$.

4. Dulbecco's modified Eagle's medium (DMEM) with 4.5g/L D-glucose, L-glutamine and pyruvate (Gibco, Thermo Fisher). Storage at $4^{\circ} \mathrm{C}$.

5. Y-27632 (Cambridge Bioscience): $5 \mathrm{mM}$ in distilled water. Storage at $-20^{\circ} \mathrm{C}$.

6. All-trans retinoic acid (Sigma): $10 \mathrm{mM}$ in $100 \% \mathrm{EtOH}$ (50 mg in $16.642 \mathrm{ml}$ ). Storage at $-80^{\circ} \mathrm{C}$ (see Note 4$)$.

7. Tracheosphere medium: $50 \%$ DMEM (no serum, no antibiotics), $50 \%$ bronchial epithelial basal medium (plus all of the BEGM supplements except amphotericin B, triiodothyronine and retinoic acid). Storage at $4^{\circ} \mathrm{C}$. Supplemented with $5 \mu \mathrm{M}$ Y-27632 for cell seeding (but not subsequent feeds). Always supplemented with $100 \mathrm{nM}$ alltrans retinoic acid at the time of use.

\subsection{Immunofluorescence Staining of Tracheospheres}

1. $4 \%(\mathrm{w} / \mathrm{v})$ paraformaldehyde in $\mathrm{PBS}$. Heat to $65^{\circ} \mathrm{C}$ to dissolve and adjust $\mathrm{pH}$ to 7.2 . 
2. HistoGel Specimen Processing Gel (Thermo Scientific; see Note 5).

3. Blocking solution (10\% FBS in PBS).

4. DAPI (4',6-diamidino-2-phenylindole; Molecular Probes). Stock solution: $10 \mu \mathrm{g} / \mathrm{ml}$.

5. Mounting medium (Immu-mount, Thermo Scientific). 


\section{Methods}

\subsection{Preparation of 3T3-J2 Feeder Layers}

1. Maintain 3T3-J2 cells at low passage numbers (see Note 6) and maintain them subconfluent (see Note 7 ) in $37^{\circ} \mathrm{C}, 5 \% \mathrm{CO}_{2}$ incubators with weekly splits of $1: 8-1: 10$.

2. For feeder layer preparation, add mitomycin C ( $4 \mu \mathrm{g} / \mathrm{ml}$; final concentration) to flasks of 3T3-J2 cells in fibroblast culture medium for 2 hours (see Note 8).

3. Wash cells with PBS, harvest cells with $0.05 \%$ trypsin-EDTA and replate at a density of at least 20,000 feeder cells $/ \mathrm{cm}^{2}$ in fibroblast culture medium (see Note 9).

4. Allow 3T3-J2 cells to adhere and spread overnight before adding epithelial cells the following day (see Note 10).

\subsection{Isolation of Human Airway Epithelial Cells}

1. Derivation of human cells should be approved by the relevant local ethics committee.

2. Human airway epithelial cells are derived from brushings or biopsies taken during bronchoscopy procedures. Samples are transported to the laboratory on ice as soon as possible.

\subsubsection{Cell seeding from brushings}

1. Brushes are collected in $15 \mathrm{ml}$ falcon tubes in transport medium.

2. Thoroughly vortex tubes to remove cells from the brush.

3. Centrifuge tubes, with brushes inside, at $300 \mathrm{xg}$ for 5 minutes.

4. Carefully remove transport medium and resuspend the cell pellet in epithelial culture medium (see Note 11).

5. Seed cell suspension on pre-prepared $\mathrm{T} 25$ feeder layers, incubate at $37^{\circ} \mathrm{C}$ $\left(5 \% \mathrm{CO}_{2}\right)$ and change the medium after two days.

6. Epithelial colonies become evident after 2-3 days (see Note 12).

\subsubsection{Cell seeding from biopsies}

1. For explant cultures, biopsies are seeded directly onto pre-prepared feeder layers with a minimal covering of epithelial culture medium (Figure 
$1 \mathrm{~A}$; see Note 13 ) or they can be digested to form a cell suspension prior to culture.

2. To digest a biopsy, carefully transfer the biopsy to an eppendorf tube containing $16 \mathrm{U} / \mathrm{ml}$ dispase in RPMI. Digest for 20 minutes at room temperature.

3. Neutralize the digestion by adding an equal volume of neutralization medium.

4. Transfer the tissue to a sterile petri dish and dissect away epithelium (see Note 14).

5. Transfer to an eppendorf containing 0.1\% trypsin-EDTA (diluted in RPMI) and incubate at $37^{\circ} \mathrm{C}$ for 30 minutes. Remove cells from the incubator and agitate by pipetting every 10 minutes.

6. Neutralize the trypsin by addition of at least the same volume of neutralization medium and pipette thoroughly.

7. Combine the neutralized digest with the neutralized dispase solution from Step 3.

8. Centrifuge cells at $300 \times g$ for 5 minutes.

9. Remove supernatant and resuspend the pellet in epithelial culture medium.

10. Seed cell suspension on pre-prepared $\mathrm{T} 25$ feeder layers, incubate at $37^{\circ} \mathrm{C}$ $\left(5 \% \mathrm{CO}_{2}\right)$ and change the medium after two days.

11. Epithelial colonies become evident after 2-3 days.

\subsection{Maintenance of Human Airway Basal Epithelial Cells}

1. During normal maintenance epithelial cells are fed with fresh complete epithelial medium three times per week (10 ml per T75 or equivalent for other vessel surface areas) and stored in $37^{\circ} \mathrm{C}, 5 \% \mathrm{CO}_{2}$ incubators.

2. Passage epithelial cell cultures at $80-90 \%$ confluence (Figure 1B).

3. Remove epithelial culture medium and wash cells once with PBS.

4. Add $0.05 \%$ trypsin-EDTA (see Note 15 ) for 2 minutes at room temperature, gently tap flasks and confirm the removal of feeder cells, which are substantially more trypsinsensitive than epithelial cells, under a microscope. 
5. Remove the trypsin and wash with PBS to remove remaining feeder cells.

6. Add $0.05 \%$ trypsin-EDTA and incubate at $37^{\circ} \mathrm{C}$ until epithelial cells detach from the flask (typically this takes 5 minutes; see Note 16).

7. Neutralize the trypsin solution with the same volume of epithelial culture medium, centrifuge at $300 \mathrm{xg}$ for 5 minutes and resuspend the pellet in epithelial culture medium.

8. For continued passage, perform a 1:5 split and seed cells onto a pre-prepared feeder layer in complete epithelial culture medium. Incubate in a $37^{\circ} \mathrm{C}, 5 \% \mathrm{CO}_{2}$ incubator.

9. To cryopreserve, freeze $0.5 \times 10^{6}$ cells/vial in $200 \mu \mathrm{l}$ total volume using Profreeze freezing medium according to the manufacturer's instructions.

\subsection{D Tracheosphere Culture}

1. Coat the base of a non-adherent 96 -well plate with $25 \%$ pre-chilled Matrigel in tracheosphere medium ( $30 \mu \mathrm{l}$ per well) and transfer to an incubator $\left(37^{\circ} \mathrm{C}, 5 \% \mathrm{CO}_{2}\right)$ for at least 20 minutes (see Note 17).

2. Differentially trypsinize cultured airway basal cells from feeder cells as described above (Step 3.3.3). For one 96-well plate, resuspend 270,000 basal cells in $7 \mathrm{ml}$ tracheosphere medium containing 5\% pre-chilled Matrigel and $5 \mu \mathrm{M}$ Y-27632. Add 65 $\mu \mathrm{l}$ cell suspension per well $(2,500$ cells per well, see Note 18$)$. Return the plate to an incubator $\left(37^{\circ} \mathrm{C}, 5 \% \mathrm{CO}_{2}\right.$; see Note 19$)$.

3. Feed cells by adding $70 \mu \mathrm{l}$ tracheosphere medium (without Y-27632) on days 3,8 and 14 of culture (Figure 2A).

4. On day 18 of culture tracheospheres are well differentiated with basal cells, goblet cells and ciliated cells present (Fig. 1; see Note 20).

\subsection{Immunofluorescence Staining of Tracheospheres}

1. To collect tracheospheres, pipette the well contents into chilled PBS on ice using 200 $\mu l$ pipette tips with the ends cut off. Centrifuge at $200 \mathrm{xg}$ for 3 minutes. Fix tracheospheres by resuspension in 4\% PFA for 30 minutes.

2. Using the same centrifuge settings, wash once with PBS and resuspend the tracheosphere pellet in pre-warmed HistoGel specimen processing gel. Pipette the 
HistoGel onto parafilm as small droplets appropriate for embedding and allow it to gel at room temperature for 10 minutes.

3. Process, embed and stain the tracheospheres according to standard histology protocols (Figure 2B-D). 


\section{Notes}

1) Batch testing of FBS for the ability to support rapid expansion and serial passage of primary human epithelial cells is essential.

2) Hydrocortisone/EGF stock is prepared by dissolving hydrocortisone at $0.5 \mathrm{mg} / \mathrm{ml}$ in $100 \%$ ethanol. $1 \mathrm{ml}$ hydrocortisone is added to $19 \mathrm{ml}$ DMEM containing $2.5 \mu \mathrm{g}$ recombinant human EGF. Hydrocortisone/EGF stock aliquots are stored at $-20^{\circ} \mathrm{C}$.

3) A bottle of Matrigel must be thawed on ice for $>6$ hours. Once thawed, Matrigel should be aliquoted into pre-chilled, sterile eppendorf tubes and stored at $-20^{\circ} \mathrm{C}$. Freeze-thaw Matrigel a maximum of three times. Matrigel should be kept on ice throughout the tracheosphere seeding process.

4) Retinoic acid is extremely light sensitive. Care should be taken to minimize light exposure during preparation and storage, for example by foil wrapping falcon tubes. Aliquotted $10 \mathrm{mM}$ stocks can be stored for up to one month at $-80^{\circ} \mathrm{C}$. We prepare a 1:1000 $(10 \mu \mathrm{M})$ stock and dilute this 1:100 to prepare tracheosphere medium (final conc. $100 \mathrm{nM})$.

5) A $10 \mathrm{ml}$ vial of HistoGel should be pre-heated to $65^{\circ} \mathrm{C}$ in a waterbath for 30 minutes. HistoGel can be aliquoted into $1.5 \mathrm{ml}$ eppendorf tubes to reduce this time to 10 minutes and sets quickly at room temperature so should be kept at $65^{\circ} \mathrm{C}$ until use.

6) We thaw fresh 3T3-J2 cells after passage 12 as the cells are susceptible to undergoing spontaneous transformation, proliferating more rapidly and adopting a cuboidal morphology compared with the usual spread appearance of fibroblasts.

7) 3T3-J2 cultures should never be allowed to become over confluent as their morphology and sensitivity to irradiation/mitomycin C can be affected, leading to poor quality feeder layers.

8) Alternatively, 3T3-J2s can be mitotically inactivated by $40 \mathrm{~Gy}$ (4000 rd) irradiation.

9) After mitotic inactivation, 3T3-J2 cells are fragile and care should be taken when pipetting the cells as excessive stress can cause feeder layers to degenerate more rapidly.

10) Co-seeding of 3T3-J2 and epithelial cells in complete epithelial culture medium produces poor quality feeder layers. Mitotically inactivated fibroblasts do not spread, as when seeded in fibroblast culture medium, and feeder layers degenerate more 
quickly. Thus, it is important to be well-organized in the planning of experiments using co-cultured cells.

11) Care should be taken to wash the brush with epithelial culture medium to free as many cells as possible. We use at least two rounds of washing with fresh medium.

12) Contamination of cultures with human fibroblasts has not been a problem in our lab. It is thought that the combination of the feeder layers and culture medium additives suppress the growth of fibroblasts.

13) We do not change the medium on explant biopsies for the first 7 days of culture in order to avoid the risk of detaching the biopsy by moving the flask. Epithelial outgrowths are normally visible in the second week and can be serially passaged as described in Step 3.3.3.

14) In practice, it is difficult to see the epithelium at this stage - after proper dispase digest the biopsy will appear 'fluffy' - but we do find that pulling apart the biopsy at this stage improves the efficiency of the trypsin step.

15) TrypLE Select (Gibco, Thermo Fisher), a recombinant trypsin that avoids the use of porcine trypsin in human cultures, can be used in place of $0.05 \%$ Trysin-EDTA for passaging epithelial cells with no negative impact on the quality of cultures.

16) Epithelial cells should be treated with care during passaging. We remove cells following trypsinization by gently tapping flasks rather than by washing. Care should also be taken to avoid excessive pipetting of epithelial cells during resuspension.

17) To maximize the well volume available for addition of culture medium, the Matrigel layer at the well base is minimal. Non-adherent culture plates are used to prevent cells in close proximity to the culture plastic from losing 3D structure.

18) Video microscopy studies indicate that tracheospheres formed from cells at this density are not clonal but multiple basal cells in the initial culture can migrate and interact to form tracheospheres.

19) Tracheospheres are very sensitive to culture conditions. We use dedicated incubators, with extra humidification, for airway differentiation assays in order to reduce the number of times incubator doors are opened and to better maintain constant humidity, $\mathrm{CO}_{2}$, etc.

20) The abundance of cilia in tracheospheres increases over time. Cilia are observed at day 14 but longer culture periods produce better results. This must be balanced with 
the ability to continue to add culture medium to wells. End-point assays can be performed between day 14 and day 21 . 

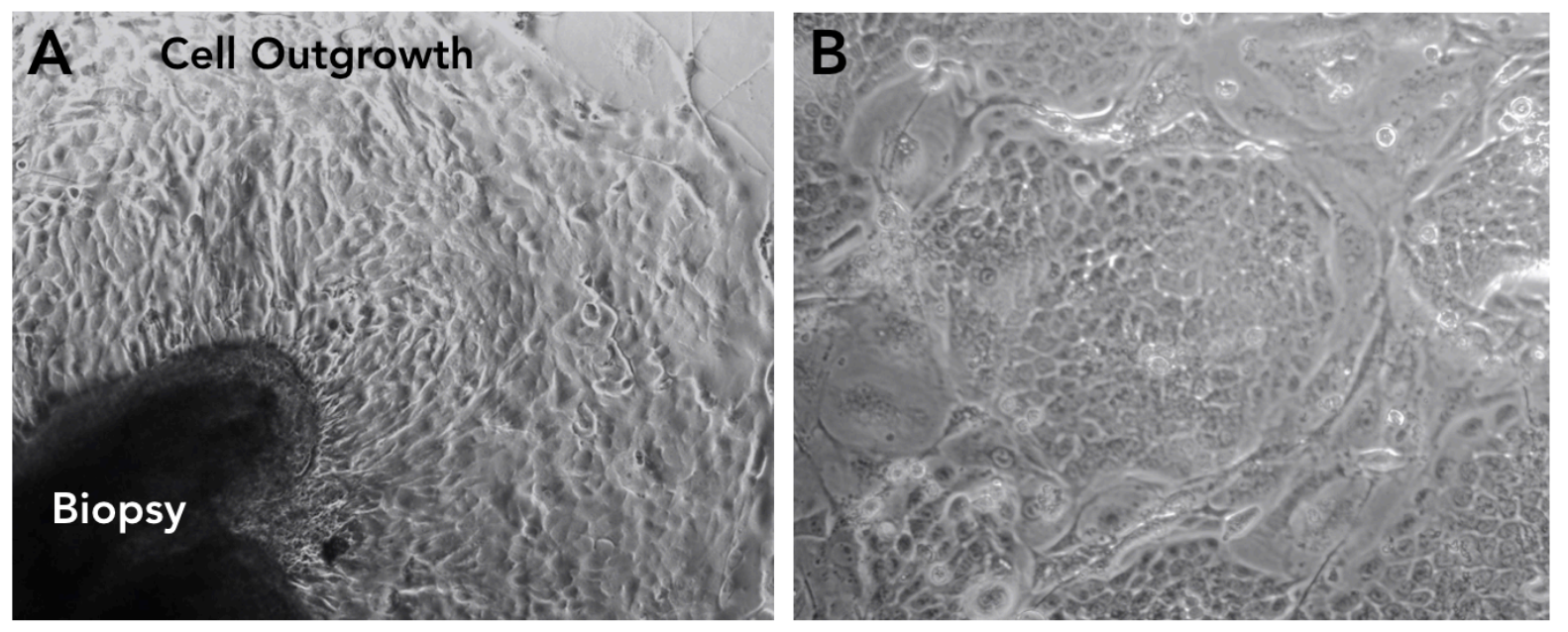

Figure 1: (A) Phase-contrast image of epithelial cell outgrowth from an endobronchial biopsy grown on a 3T3-J2 feeder layer in medium containing the ROCK inhibitor Y-27632 (3T3+Y). (B) Phase-contrast image of colonies of sub-cultured human airway epithelial cells grown in $3 T 3+Y$. 

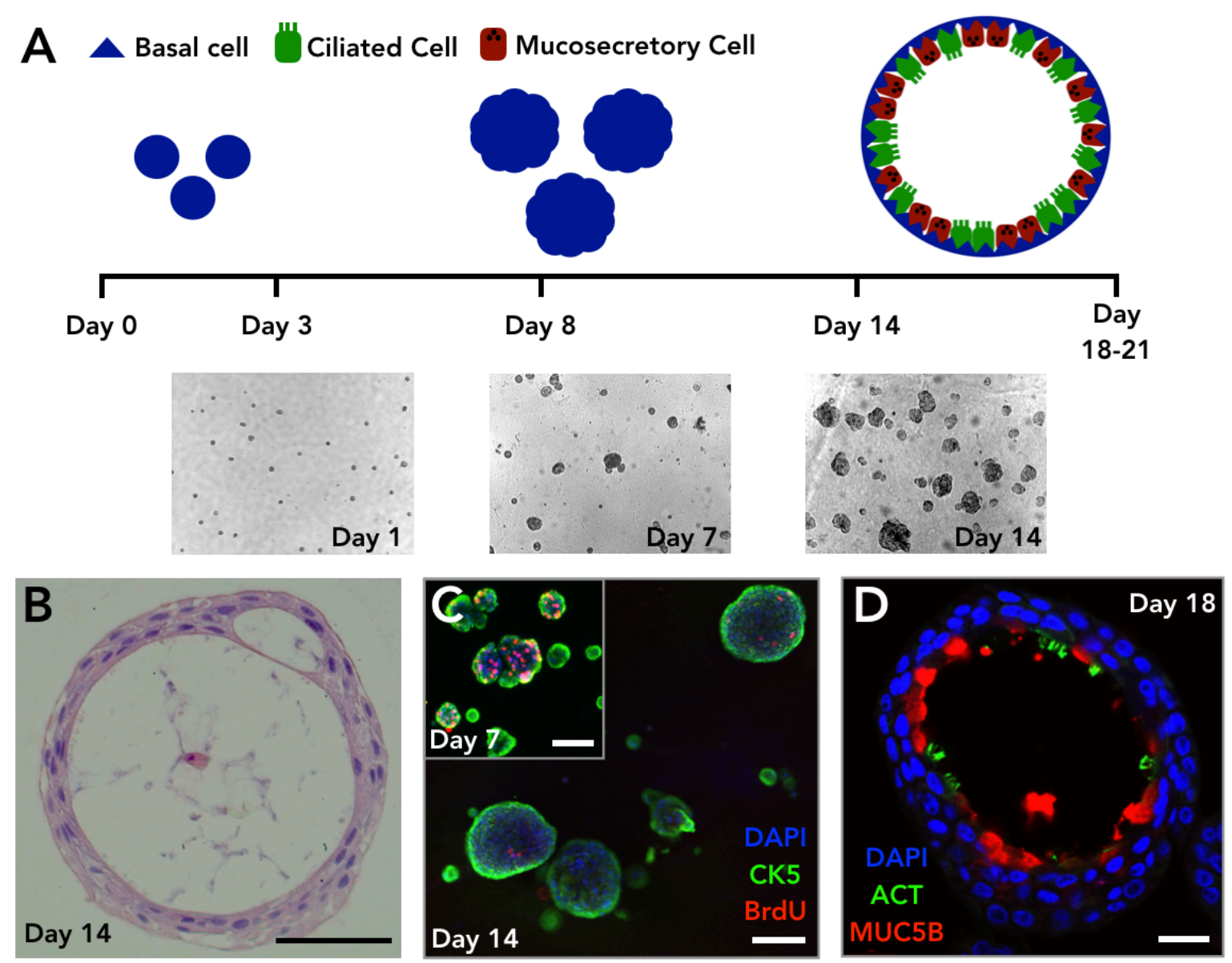

Figure 2: (A) Schematic representation of airway tracheosphere formation in 3D Matrigel culture with brightfield images showing the time course of tracheosphere growth. (B) Haematoxylin and eosin (H\&E) staining of a tracheosphere. Scale bar $=50 \mu \mathrm{m}$. (C) Wholemount immunofluorescence staining of tracheospheres at day 7 and day 14 shows that BrdU uptake is high in the early stages of culture, as tracheospheres form, but reduces over time. Scale bar $=100 \mu \mathrm{m}$. (D) Immunofluorescence staining of tracheospheres shows the differentiation of cultured primary human airway basal cells into both ciliated (ACT; green) and mucosecretory (MUC5B; red) cells in tracheospheres. Scale bar $=20 \mu \mathrm{m}$. 


\section{Acknowledgments}

We thank Prof. Richard Schlegel (Georgetown University, U.S.A.), Dr. Xuefeng Liu (Georgetown University, U.S.A.) and Dr. Henry Danahay (University of Sussex, U.K.) for sharing their laboratories protocols during the development of those described here.

This work was supported by a BBSRC-CASE studentship with industrial support from Unilever (R.E.H.), a Wellcome Trust Clinical Research Fellowship (C.R.B), an ERC Starting Grant (A.G.), a Wellcome Trust Senior Fellowship (S.M.J.) and was undertaken at UCLH/UCL who receive funding from the Department of Health's NIHR Biomedical Research Centre's funding scheme and the UCL Experimental Cancer Medicine Centre (S.M.J.). 


\section{References}

1. Hogan, B. L., Barkauskas, C. E., Chapman, H. A., Epstein, J. A., Jain, R., Hsia, C. C., Niklason, L., Calle, E., Le, A., Randell, S. H., Rock, J., Snitow, M., Krummel, M., Stripp, B. R., Vu, T., White, E. S., Whitsett, J. A., and Morrisey, E. E. (2014). Repair and regeneration of the respiratory system: complexity, plasticity, and mechanisms of lung stem cell function. Cell Stem Cell, 15, 123-138

2. Rock, J. R., Onaitis, M. W., Rawlins, E. L., Lu, Y., Clark, C. P., Xue, Y., Randell, S. H., and Hogan, B. L. (2009). Basal cells as stem cells of the mouse trachea and human airway epithelium. Proc Natl Acad Sci U S A, 106, 12771-12775

3. Teixeira, V. H., Nadarajan, P., Graham, T. A., Pipinikas, C. P., Brown, J. M., Falzon, M., Nye, E., Poulsom, R., Lawrence, D., Wright, N. A., McDonald, S., Giangreco, A., Simons, B. D., and Janes, S. M. (2013). Stochastic homeostasis in human airway epithelium is achieved by neutral competition of basal cell progenitors. Elife, 2, e00966

4. Hynds, R. E., and Giangreco, A. (2013). Concise review: the relevance of human stem cellderived organoid models for epithelial translational medicine. Stem Cells, 31, 417-422

5. de Jong, P. M., van Sterkenburg, M. A., Hesseling, S. C., Kempenaar, J. A., Mulder, A. A., Mommaas, A. M., Dijkman, J. H., and Ponec, M. (1994). Ciliogenesis in human bronchial epithelial cells cultured at the air-liquid interface. Am J Respir Cell Mol Biol, 10, 271-277

6. Fulcher, M. L., Gabriel, S., Burns, K. A., Yankaskas, J. R., and Randell, S. H. (2005). Welldifferentiated human airway epithelial cell cultures. Methods Mol Med, 107, 183-206

7. Mathis, C., Poussin, C., Weisensee, D., Gebel, S., Hengstermann, A., Sewer, A., Belcastro, V., Xiang, Y., Ansari, S., Wagner, S., Hoeng, J., and Peitsch, M. C. (2013). Human bronchial epithelial cells exposed in vitro to cigarette smoke at the air-liquid interface resemble bronchial epithelium from human smokers. Am J Physiol Lung Cell Mol Physiol, 304, L489-503

8. Rheinwald, J. G., and Green, H. (1975). Serial cultivation of strains of human epidermal keratinocytes: the formation of keratinizing colonies from single cells. Cell, 6, 331-343

9. Chapman, S., Liu, X., Meyers, C., Schlegel, R., and McBride, A. A. (2010). Human keratinocytes are efficiently immortalized by a Rho kinase inhibitor. J Clin Invest, 120, 2619-2626

10. Suprynowicz, F. A., Upadhyay, G., Krawczyk, E., Kramer, S. C., Hebert, J. D., Liu, X., Yuan, H., Cheluvaraju, C., Clapp, P. W., Boucher, R. C., Jr., Kamonjoh, C. M., Randell, S. H., and Schlegel, R. (2012). Conditionally reprogrammed cells represent a stem-like state of adult epithelial cells. Proc Natl Acad Sci U S A, 109, 20035-20040

11. Liu, X., Ory, V., Chapman, S., Yuan, H., Albanese, C., Kallakury, B., Timofeeva, O. A., Nealon, C., Dakic, A., Simic, V., Haddad, B. R., Rhim, J. S., Dritschilo, A., Riegel, A., McBride, A., and Schlegel, R. (2012). ROCK inhibitor and feeder cells induce the conditional reprogramming of epithelial cells. Am J Pathol, 180, 599-607

12. Butler, C. R., Hynds, R. E., Gowers, K. H., Lee, D. D., Brown, J. M., Crowley, C., Teixeira, V. H., Smith, C. M., Urbani, L., Hamilton, N. J., Thakrar, R. M., Booth, H. L., Birchall, M. A., De Coppi, P., Giangreco, A., O'Callaghan, C., and Janes, S. M. (2016). Rapid Expansion of Human Epithelial Stem Cells Suitable for Airway Tissue Engineering. Am J Respir Crit Care Med (in press).

13. Wu, X., Peters-Hall, J. R., Bose, S., Pena, M. T., and Rose, M. C. (2011). Human bronchial epithelial cells differentiate to 3D glandular acini on basement membrane matrix. Am J Respir Cell Mol Biol, 44, 914-921

14. Hegab, A. E., Ha, V. L., Darmawan, D. O., Gilbert, J. L., Ooi, A. T., Attiga, Y. S., Bisht, B., Nickerson, D. W., and Gomperts, B. N. (2012). Isolation and in vitro characterization of basal and submucosal gland duct stem/progenitor cells from human proximal airways. Stem Cells Transl Med, 1, 719-724

15. Danahay, H., Pessotti, A. D., Coote, J., Montgomery, B. E., Xia, D., Wilson, A., Yang, H., Wang, Z., Bevan, L., Thomas, C., Petit, S., London, A., LeMotte, P., Doelemeyer, A., Velez-Reyes, G. 
L., Bernasconi, P., Fryer, C. J., Edwards, M., Capodieci, P., Chen, A., Hild, M., and Jaffe, A. B. (2015). Notch2 is required for inflammatory cytokine-driven goblet cell metaplasia in the lung. Cell Rep, 10, 239-252

16. Gao, X., Bali, A. S., Randell, S. H., and Hogan, B. L. (2015). GRHL2 coordinates regeneration of a polarized mucociliary epithelium from basal stem cells. J Cell Biol, 211, 669-682 